\title{
ASPECTOS SEMÁNTICOS EN LOS ENTORNOS VIRTUALES DE FORMACIÓN
}

\section{Resumen:}

La semántica es un elemento necesario en cualquier actividad de aprendizaje, independientemente del contexto en el que nos encontremos. Los entornos virtuales de formación, como instituciones sociales mediadas por tecnología, tienen también una semántica asociada, que muchas veces es poco valorada por las personas que los diseñan. El componente semántico en estos entornos facilita la negociación de significados, que debe ocurrir para que los estudiantes puedan apropiarse de conocimiento y asociarlo con alguno de los patrones semánticos que ya posee, o crear uno nuevo. Se muestran aquí los aspectos semánticos que deben estar presentes en los entornos virtuales de formación, para situar al estudiante en el contexto semántico propuesto por el docente y que lo conduzca a un aprendizaje significativo.

Palabras clave: semántica, entornos virtuales de formación, andamiaje.

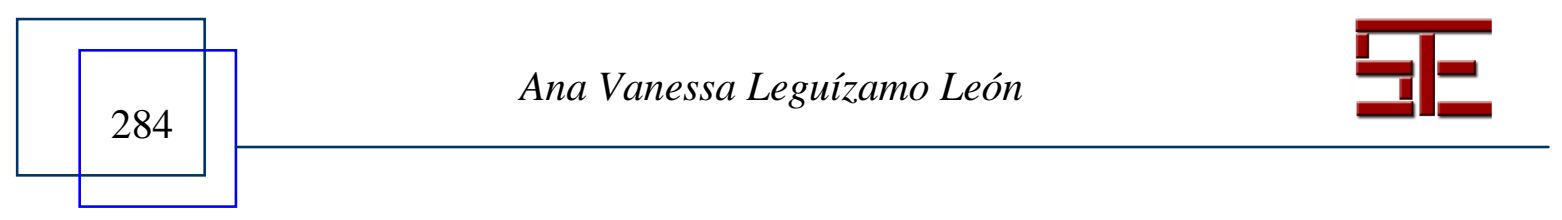




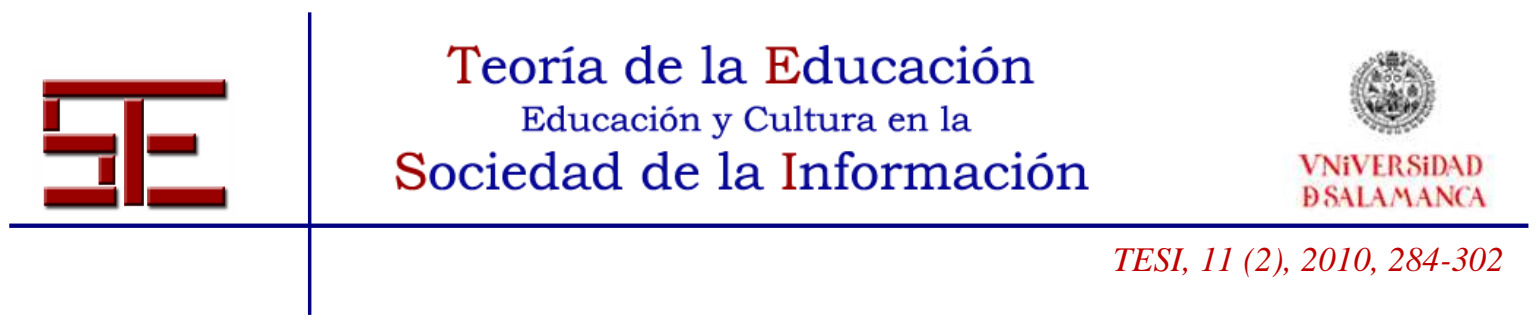

\section{SEMANTIC ISSUES IN VIRTUAL LEARNING ENVIRONMENTS}

Abstract:

The semantic is a necessary element in any learning activity, regardless of the context in which we are. Virtual learning environments, as social institutions mediated by technology, also have semantic, which is often underrated by the people who designed them. In these environments, the semantic component facilitates the meaning negotiation, which must occur in students to acquire their knowledge and associate it with any of their semantic patterns, or create a new one. Here shown that semantic issues must be present in virtual learning environments, to place the student in the semantic context proposed by the teacher and that leads to a significant learning.

Keywords: semantic, virtual learning environments, scaffolding.

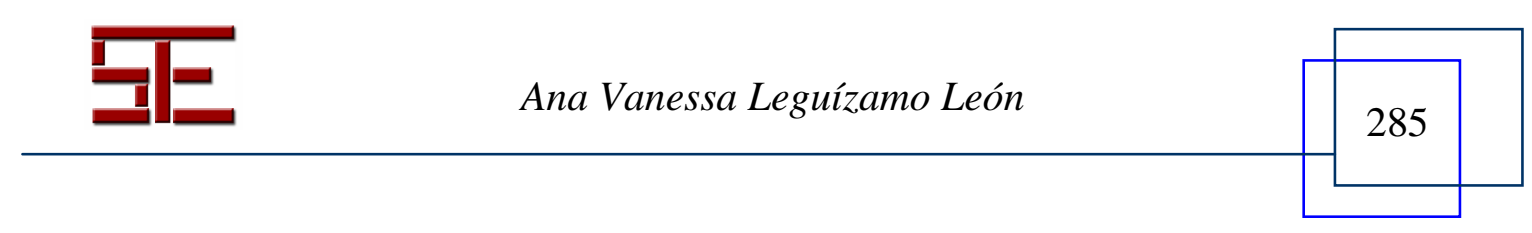




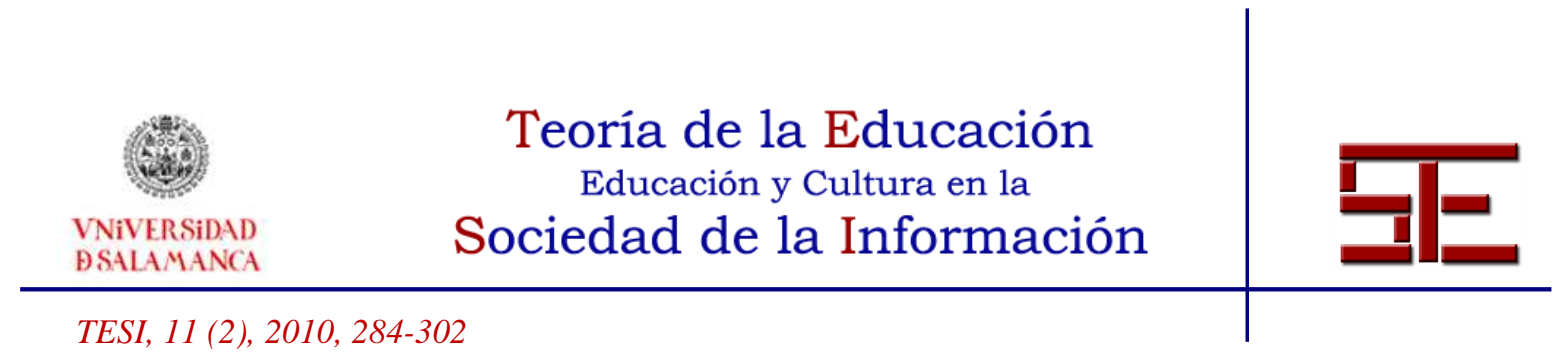

\section{ASPECTOS SEMÁNTICOS EN LOS ENTORNOS VIRTUALES DE FORMACIÓN}

Fecha de recepción: 19/06/2009; fecha de aceptación: 31/03/2010; fecha de publicación: 05/07/2010

Ana Vanessa Leguízamo León

vanessa.leguizamo@ciens.ucv.ve

Universidad Central de Venezuela.

\section{1.- INTRODUCCIÓN}

La semántica surge naturalmente en cualquier contexto en el que nos encontremos. El hecho de que identifiquemos un objeto y su función es producto de lo que representa y la interpretación que nosotros hacemos de esa imagen que se nos presenta. En el campo educativo sucede exactamente igual. Al impartir conceptos a nuestros estudiantes, existe una intencionalidad de nuestra parte y estructuramos los contenidos de una manera que consideramos adecuada, pero los estudiantes, que tienen su propia estructura mental, se apropian de esa información de acuerdo a la interpretación que le den y de cómo logren acoplar este nuevo conocimiento a su estructura mental. De aquí que ese componente semántico, que provoca la interpretación de todo cuanto percibimos, sea de especial interés al momento de situarnos en un contexto de enseñanza-aprendizaje, ya que facilitará, o por el contrario, entorpecerá, la apropiación de conocimientos por parte de los estudiantes.

Los entornos virtuales de formación están constantemente en evolución, valiéndose, entre otras cosas, de los elementos tecnológicos que le sean útiles. Así, incorporan objetos digitales que han sido desarrollados por informáticos, quienes tienen una visión más técnica de la semántica. El concepto de semántica en el campo de la informática hace referencia al conjunto de reglas que especifican el significado de cualquier sentencia o estructura formal que sea sintácticamente válida (Aho et al., 1990). El análisis semántico realizado a los programas de computación se lleva a cabo en función de una gramática libre de contexto para determinar cuáles sentencias no pertenecen semánticamente al lenguaje, independientemente del contexto en el cual se ejecute posteriormente el programa.

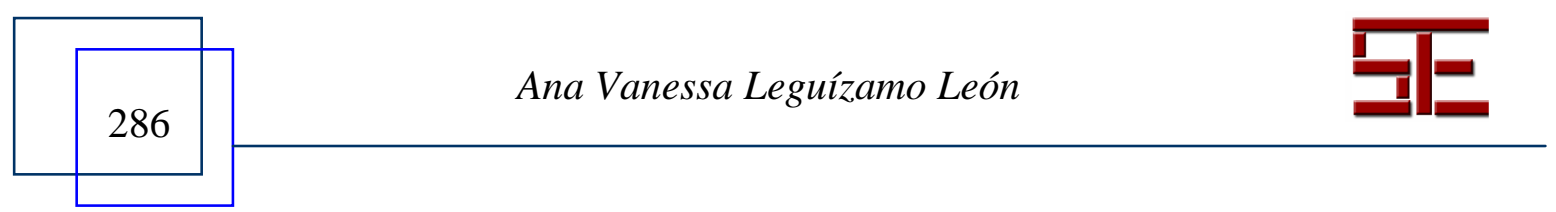




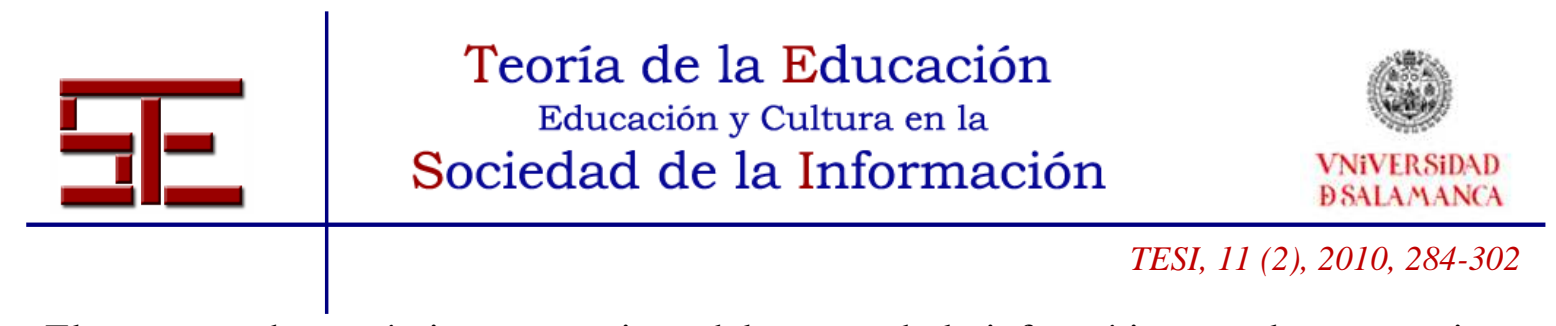

El concepto de semántica no proviene del campo de la informática, por lo que no tiene el mismo significado en este contexto, o en uno educativo, como es nuestro caso. La semántica implica una negociación de significados, por lo que el significado semántico de una palabra es relativo al contexto en el cual se encuentre, así se puede tener palabras sintácticamente idénticas, pero que, dependiendo del contexto en el que se utilicen, tengan significados diferentes. Los contextos educativos son naturalmente semánticos, ya que el aprendizaje requiere la adquisición de conceptos, habilidades y destrezas, para lo que necesariamente se da una negociación entre lo impartido por el docente y de lo que finalmente se apropia el estudiante en la búsqueda de significación, relacionando lo nuevo con los esquemas que ya posee.

En función de lo anteriormente descrito, partimos de que la necesaria negociación de significados que debe ocurrir en un entorno virtual de formación no tiene como base, meramente, una solución algorítmica, por lo que inicialmente debemos conocer de qué manera se construye esa negociación de significados y cuáles elementos la promueven. En este trabajo se presenta un acercamiento a la inclusión del componente semántico en los entornos virtuales de formación. Para ello, el artículo se ha estructurado de la siguiente manera: En el apartado 2 se introducen los entornos virtuales de formación, desde el punto de vista de su constitución como institución social mediada por tecnología. En el apartado 3 se presenta una descripción del aspecto semántico en los entornos virtuales de formación, para llegar al concepto de semanticidad que se manejará en el trabajo. En el apartado 4 se discute el enfoque semántico como elemento de negociación de significados en entornos virtuales de formación. Finalmente, se presentan las conclusiones del trabajo.

\section{2.- ENTORNOS VIRTUALES DE FORMACIÓN}

La investigación pedagógica no sólo ha incidido sobre la presentación de objetos de formación y su contexto semántico, sino que ha promovido, porque la tecnología lo hace posible, la construcción de auténticos escenarios de formación completos. Las posibilidades de la tecnología digital reconstruyen el propio concepto de institución formativa. Una institución, en la tradición jurídica, desde Maurice Hauriou (1925), es un proyecto colectivo que toma cuerpo social. En nuestro caso, se trata de un proyecto de formación, cuyo cuerpo social tradicional lo constituyen las instituciones educativas (los centros de formación). La tecnología digital permite la creación de entornos de práctica formativa mediados por esa tecnología, con capacidad de diseños completos de formación. Habitualmente se denominan "virtuales", porque no son escenarios cara a cara, ni transcurren dentro de un espacio físico. Es obvio, sin embargo, que en estos entornos, construidos con tecnología digital, tiene lugar una comunicación real y se desarrollan prácticas y actividades reales de formación. Se trata pues, de instituciones

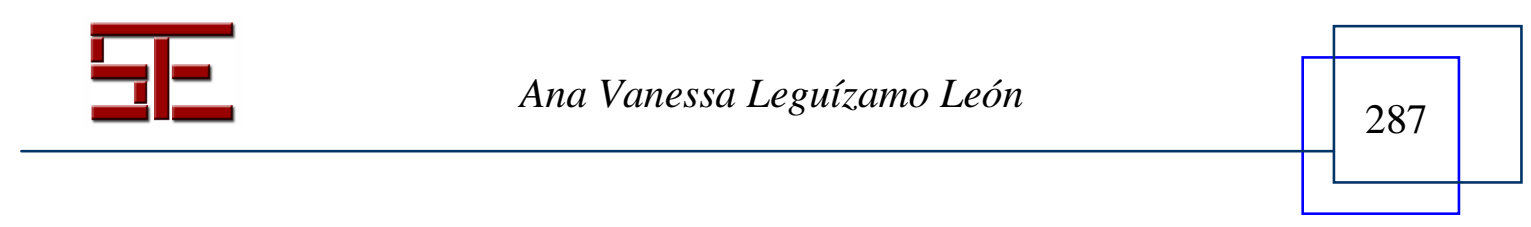




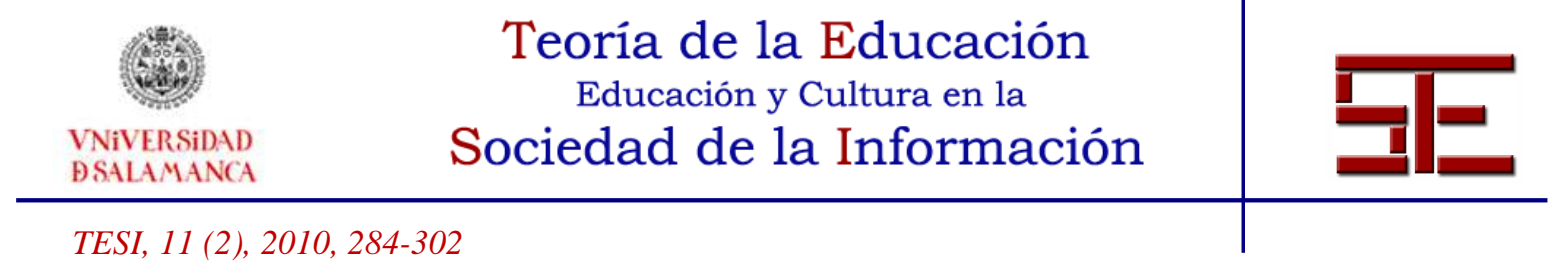

particulares, dada la particularidad de sus mediaciones comunicacionales; pero siguen siendo también instituciones reales.

Según Martín-Barbero (2003) la tecnología remite hoy a nuevos modos de percepción y de lenguaje, a nuevas sensibilidades y escrituras. La tecnología deslocaliza los saberes modificando el estatuto cognitivo e institucional de las condiciones del saber, haciendo difusas las fronteras entre razón e imaginación, saber e información, naturaleza y artificio, arte y ciencia. Lo que la trama comunicativa de la revolución tecnológica introduce en nuestras sociedades no es sólo unas máquinas, cada vez más rápidas y poderosas, sino un nuevo modo de relación entre los procesos simbólicos y las formas de producción y distribución de los bienes y servicios. La "sociedad de la información" no sólo es aquella en la cual la materia prima es el conocimiento, sino también aquella en la que el desarrollo económico, social e intelectual se hallan estrechamente ligados a la creatividad y a la invención, incluso de instituciones de formación mediadas por la tecnología.

Desde una perspectiva histórica, el saber había conservado el carácter de ser centralizado, controlado por dispositivos técnico-políticos, asociado a figuras sociales de rango especial y a instituciones sociales perfectamente identificables por la comunidad, tipificando etnográficamente la comunidad de prácticas culturales. De allí que las transformaciones en los modos en que circula la información y los cambios en las instituciones constituyan una de las más profundas transformaciones que una sociedad pueda sufrir. La dispersión del saber, de la que se culpa a los medios, adquiere un nuevo sentido, ya que escapa a los mecanismos de control y reproducción imperantes en sus formas originales de circulación. El saber se descentra, en primer lugar, por relación al que ha sido su eje por mucho tiempo: el libro. Este modelo que había dirigido la práctica escolar desde la invención de la imprenta sufre una mutación cuyo alcance lo evidencia la aparición de la hipertextualidad. Son cambios que no pretenden sustituir al libro, sino relevarlo de la centralidad ordenadora de las etapas y modos de saber que la estructura del libro había impuesto al modelo de aprendizaje: linealidad de izquierda a derecha y verticalidad de arriba abajo, tanto física y mental, como espacial y simbólica.

La aparición del hipertexto motivó a los educadores a utilizarlo como herramienta en el proceso de enseñanza-aprendizaje, haciendo alusión al concepto de pie de página presente en los libros. Sin embargo, esta tecnología fue evolucionando rápidamente y se empezó entonces a incorporar elementos a estos materiales hipertextuales con la intención de que otorgaran mayores facilidades para la transmisión de conocimiento. Surge lo que se conoce como materiales multimedia, donde, además del hipertexto, se incluyen elementos audiovisuales que potencian el proceso de transmisión de

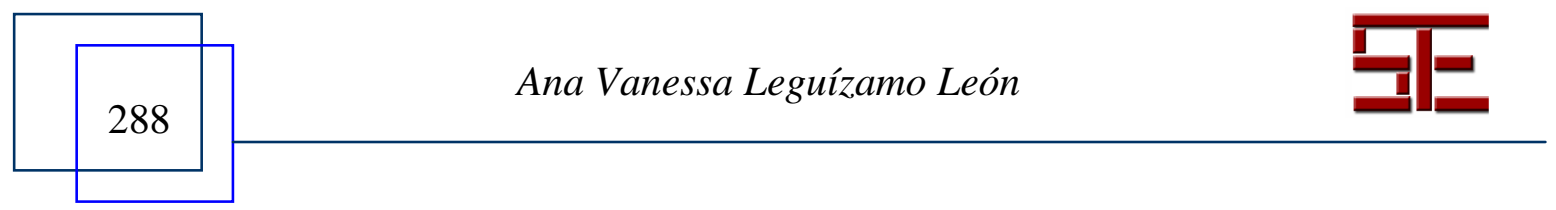




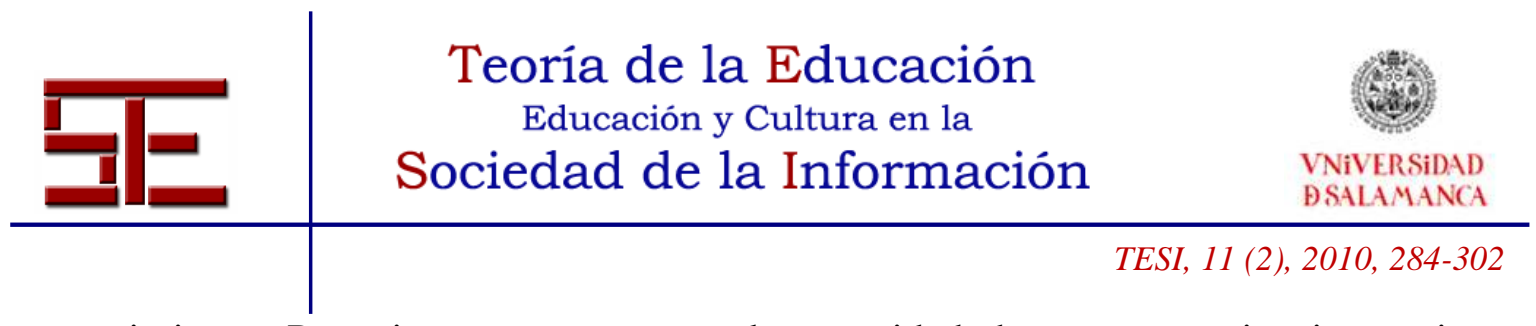

conocimiento. Posteriormente se genera la necesidad de tener espacios interactivos donde sea posible establecer comunicación efectiva entre el profesor y los estudiantes, y a su vez entre éstos para realizar tareas de manera colaborativa, por lo que se incorporan herramientas para la comunicación y colaboración tales como los foros, chats o wikis. Estas estructuras hipertextuales, así como los sistemas de comunicación y cooperación, mediadas por tecnología digital, han ido dando formas renovadas e innovadoras a los proyectos institucionales convencionales, integrándolos.

$\mathrm{Al}$ contar con este conjunto de herramientas y aplicando metafóricamente el concepto de espacio educativo, el entorno de formación suele ser definido como el sitio donde el aprendizaje tiene lugar y, basándose en que el núcleo del proceso de enseñanza consiste en el diseño de ambientes donde los alumnos pueden interactuar y estudiar de qué manera aprender, aparece al concepto técnico de entornos virtuales de formación (llamado también aprendizaje en red, teleformación, e-learning, aprendizaje virtual, etc.) donde se hace referencia en general a la formación que utiliza la Red como tecnología de distribución de información, donde la mayoría de la instrucción y de las evaluaciones se logran a través de recursos accesibles en la Web. Estos entornos virtuales se presentan como una de las estrategias formativas reales, que pueden resolver muchos problemas educativos, que van desde el aislamiento geográfico del estudiante de los centros educativos hasta la necesidad de formación continuada que introduce la sociedad del conocimiento, sin olvidar el ahorro de tiempo y dinero que supone, o la magia del mundo interactivo que ofrece.

Las definiciones existentes en la bibliografía sobre entornos virtuales son, en general, muy diferentes. Suelen coincidir en los descriptores de formación a distancia, en red, basada en tecnologías de la información y comunicación y apoyadas en Internet, sin hacer mayor énfasis en los elementos pedagógicos y de interacción que deben estar presentes en este tipo de ambientes, potenciándolos o limitándolos. Una definición clásica es la ofrecida por Cabero (2006, 2): "Podemos decir que la formación basada en red se refiere a una modalidad formativa a distancia que se apoya en la red, y que facilita la comunicación entre el profesor y los alumnos según determinadas herramientas sincrónicas y asincrónicas de la comunicación".

Una de las definiciones más completa es la propuesta por Ozollo \& Osimani $(2007,2)$, donde establecen que un entorno de formación virtual "será aquel escenario de significaciones compartidas en las que se establecen estrategias de enseñanza y comunicacionales para provocar estrategias de aprendizaje e interacciones ricas en significación respecto al conocimiento que se desea construir. Para ello se desarrolla la intencionalidad educativa en una estructura en la cual se combinan diversos lenguajes de manera atractiva y se organiza a través de conexiones o enlaces y en el cual es

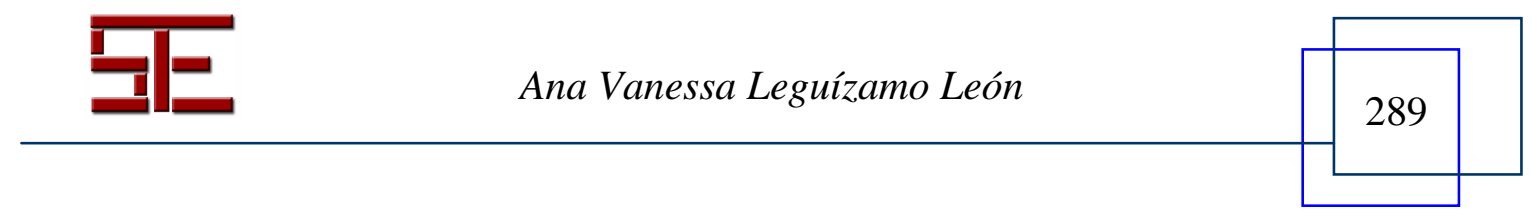




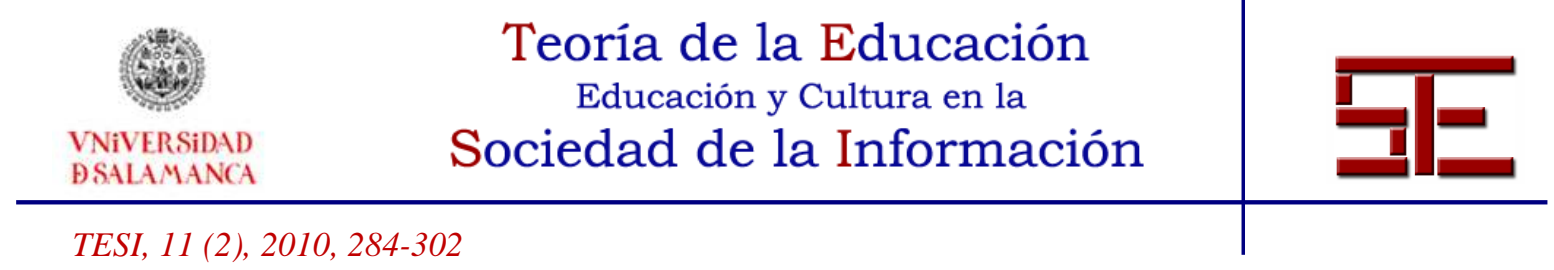

posible que el usuario tome decisiones respecto al camino a seguir por su alto grado de interactividad y movimiento con sentido". En esta definición se explicita que un entorno de formación virtual debe contar con una intencionalidad educativa, en función de la cual se debe promover una negociación de significados utilizando para ello estrategias para la enseñanza adecuadas al entorno virtual, apoyándose en estrategias comunicacionales propias de este medio.

En algunas definiciones se maximiza el componente de alfabetización tecnológica necesaria para la práctica en estos escenarios mediados por tecnología digital. Se olvida, sin embargo, que en los escenarios tradicionales de formación, el entrenamiento y la alfabetización lectoescritora constituían un requisito imprescindible de las instituciones educativas, porque la mediación lectoescritora necesaria terminaba por hacerse invisible (Gros, 2000).

Es importante resaltar en este contexto que, tal como indicó Bruner $(1984,120)$ "lo natural después de aprender a utilizar cualquier herramienta está tan determinado o más por la propia herramienta como por el usuario", por lo que la potencialidad que pueda ofrecer el entorno virtual al estudiante determinará en buena manera el rendimiento y la apropiación que éste haga del conocimiento impartido.

\section{3.- LA SEMÁNTICA EN LOS ENTORNOS VIRTUALES DE FORMACIÓN}

Los entornos virtuales de formación, al igual que cualquier ambiente donde se realice una actividad formativa requieren ciertos elementos clave que permitan la comunicación y el entendimiento, la acción comunicativa que lleva al consenso sobre la práctica de formación entre los estudiantes y entre éstos y sus profesores, para que la experiencia se desarrolle de manera exitosa. De ahí que el desarrollo de la actividad en un entorno virtual de formación tenga un ineludible proceso de comunicación no distorsionada y un componente, también ineludible, de proceso estratégico en vistas a la consumación exitosa del proyecto y no al infortunio de su fracaso.

\section{1.- La semántica en el contexto informático}

Partiendo del hecho de que al incluir el término "virtual" a la frase entorno de formación automáticamente nos referimos a un sistema de computación, desarrollado en un lenguaje de programación particular, con accesos a bases de datos para almacenar la información que allí se genera y que además debe ofrecer una interfaz gráfica que refleje una metáfora educativa, que auxilie la memoria de los estudiantes y logre involucrarlos en él. Estos sistemas de computación son elaborados por personas con

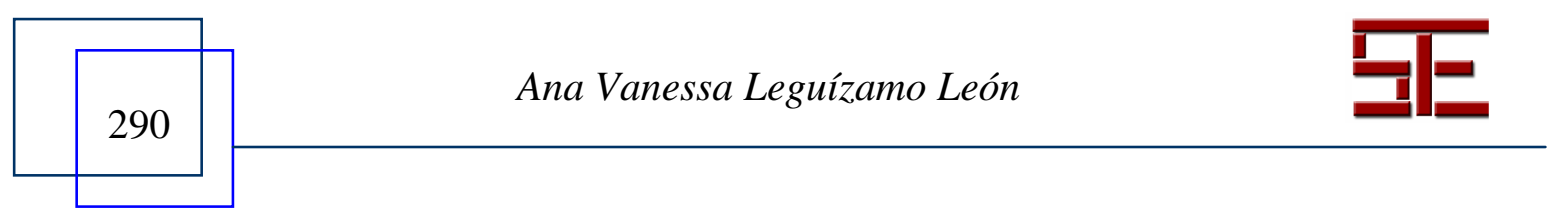




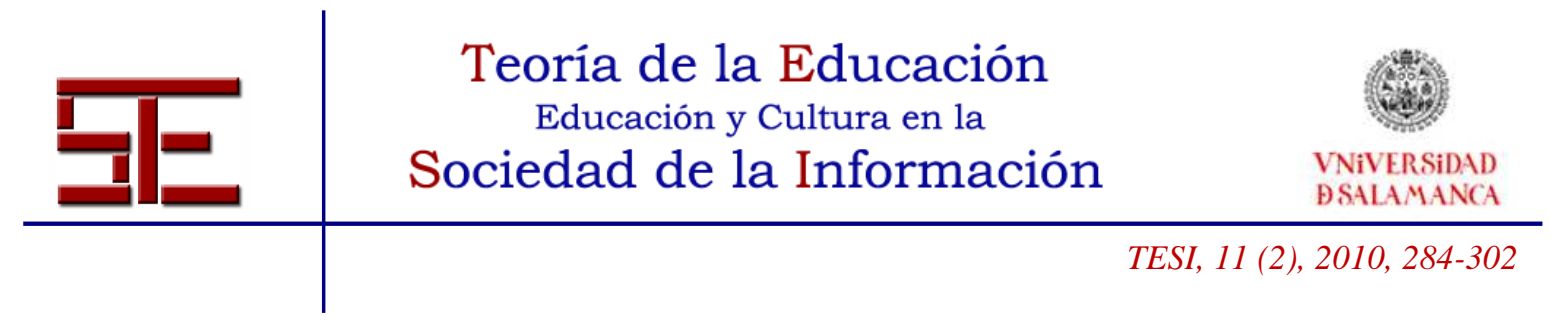

formación informática, utilizando metodologías de desarrollo establecidas, mediante la construcción de algoritmos que reflejan el manejo de la información allí contenida y que reaccionan a los eventos generados por sus usuarios. Los algoritmos deben representar el flujo de trabajo que lleva a cabo un estudiante y/o profesor para realizar sus tareas en el entorno de formación son implementados en un lenguaje de programación particular. Los lenguajes de programación, utilizados para construir cualquier tipo de software, haciendo referencia a los lenguajes naturales, definen una gramática para su correcto funcionamiento, incluyendo su sintaxis y semántica para la construcción y ejecución de las instrucciones que allí se contemplan. Según Ortín et al. (2004) la sintaxis de un lenguaje de programación es el conjunto de reglas formales que especifican la estructura de los programas construidos con ese lenguaje. La semántica por su parte es el conjunto de reglas que especifican el significado de cualquier sentencia que sea sintácticamente válida. En este contexto el concepto de semántica se emplea en el sentido de que se trata de una programación dirigida a la construcción de "objetos digitales", programa digital, con el cual sea posible realizar las operaciones que determinan los objetivos de la programación.

Para verificar que el programa es semánticamente correcto se realiza un análisis semántico, que consiste en detectar la validez operacional de las sentencias aceptadas por el analizador sintáctico: la lógica de las operaciones que constituirán el programa. La fase de análisis semántico revisa el código del programa para encontrar errores semánticos y reúne la información sobre los tipos de dato para la fase posterior de generación de código. Aquí, el compilador verifica si cada operador tiene operandos permitidos por la especificación del lenguaje de programación, independientemente del contexto en el cual se ejecute posteriormente el programa. Sin embargo, la programación de las estructuras digitales de un entorno virtual implica, en sí misma, la creación de un contexto de actividad, con posibilidades y límites. De ahí que la formulación de los objetivos finales de la programación digital (sintaxis) requiera la condición previa de explicitar el contexto de actividad pedagógica que dirigirá todas las operaciones. Por esta razón, es pertinente plantearse en estos entornos no sólo las cuestiones de calidad técnica (sintaxis), sino también las de calidad de los diseños y sus limitaciones potenciales (semántica). Finalmente, todo indica que el valor final de una práctica mediada por la tecnología no estriba en lo avanzado de la tecnología empleada, sino en la calidad de los diseños de la práctica formativa que con ella se promueve.

\section{2.- La semántica en el contexto educativo}

El concepto de semántica no proviene del campo de la informática, por lo que no tiene el mismo significado en este contexto o en uno educativo, como es nuestro caso. La semántica es parte integral de la gramática de cualquier lengua y hace referencia a los

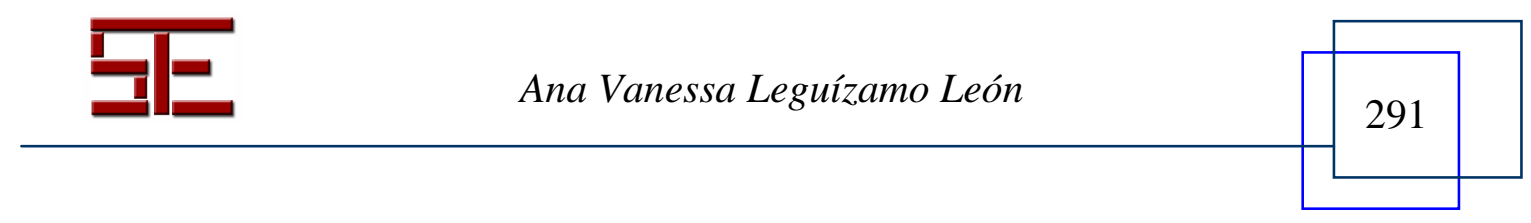




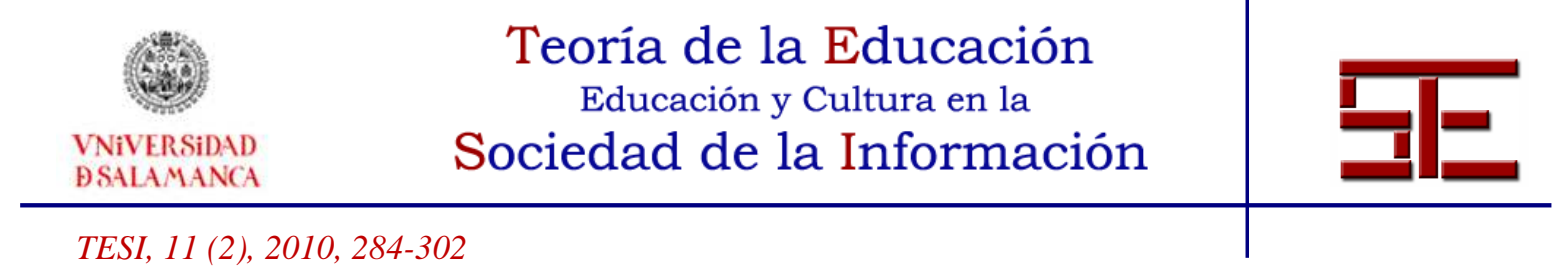

aspectos del significado o interpretación del significado de un determinado símbolo, palabra, lenguaje o representación formal, y examina el modo en que los significados se atribuyen a las palabras, sus modificaciones a través del tiempo y también sus cambios por nuevos significados, de ser el caso. La semántica implica una negociación de significados, por lo que el significado semántico de una palabra es relativo al contexto en el cual se encuentre; así se puede tener palabras sintácticamente idénticas, pero que, dependiendo del contexto en el que se utilicen, tengan significados diferentes.

Los contextos educativos son naturalmente semánticos, ya que el aprendizaje requiere la adquisición de conceptos, habilidades y destrezas, para lo que necesariamente se debe dar una negociación entre los significados de lo impartido por el docente y lo que finalmente se apropia el estudiante. La cuestión final de la semanticidad en la tecnología se estipula mediante los usos reales a los que se aplica la tecnología o mediante los límites reales que la tecnología presenta. En este momento la experiencia nos indica que, en muchos casos, las virtualidades y posibilidades semánticas son superiores a las que presentan los usos. De ahí el sentido de nuestra investigación, la cual pretende plantear heurísticas de expansión de la semanticidad dentro de las posibilidades tecnológicas disponibles y a la mano de la mayor parte de los usuarios docentes.

En esta dirección se han realizado esfuerzos por dotar de cierto grado de semántica a los entornos virtuales de formación, particularmente en el caso de los objetos que allí se incorporan. Surge así el concepto de Objeto de Aprendizaje, definido en Morales (2007, 55) como "una unidad educativa con un objetivo mínimo de aprendizaje asociado a un tipo concreto de contenido y actividades para su logro, caracterizada por ser digital, independiente, y accesible a través de metadatos con la finalidad de ser reutilizadas en diferentes contextos y plataformas". Un objeto de aprendizaje puede ser cualquier unidad digital que tenga un contenido pedagógico, desde una imagen, pasando por una simulación hasta un software completo. Dada la variedad de tipos de objetos de aprendizaje y del tamaño que pueden tener, se etiquetan usando metadatos, que son descripciones del contenido y funcionamiento de los objetos digitales que se añaden a éstos con la intención de facilitar su búsqueda, conocer a priori si puede ser útil su incorporación en un entorno de formación y que consisten en etiquetas que son descritas en un metalenguaje particular para que puedan ser interpretadas por los ordenadores. Estos metadatos permiten también realizar una clasificación de los objetos en función de categorías, que pueden ser definidas por el docente de acuerdo a sus intereses. Con estas categorías sería posible también realizar asociaciones entre los materiales, definir las propiedades educativas o pedagógicas de los documentos, o el orden en el que los estudiantes deben acceder a ellos. Al incorporar este tipo de elementos semánticos a los materiales que realizan los docentes y reflejando las relaciones entre ellos, un sistema

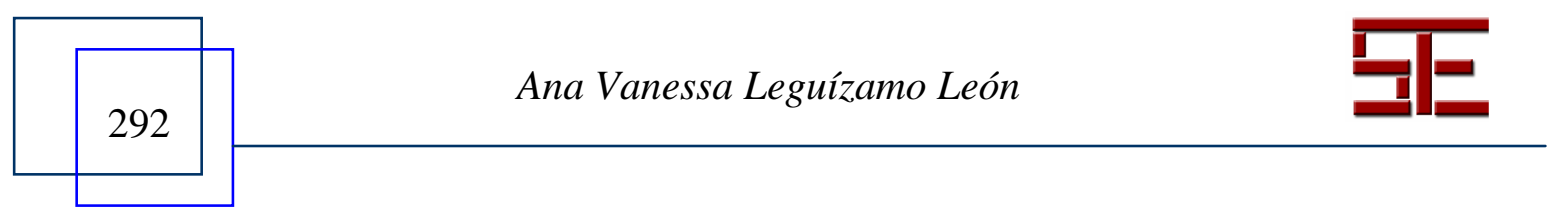




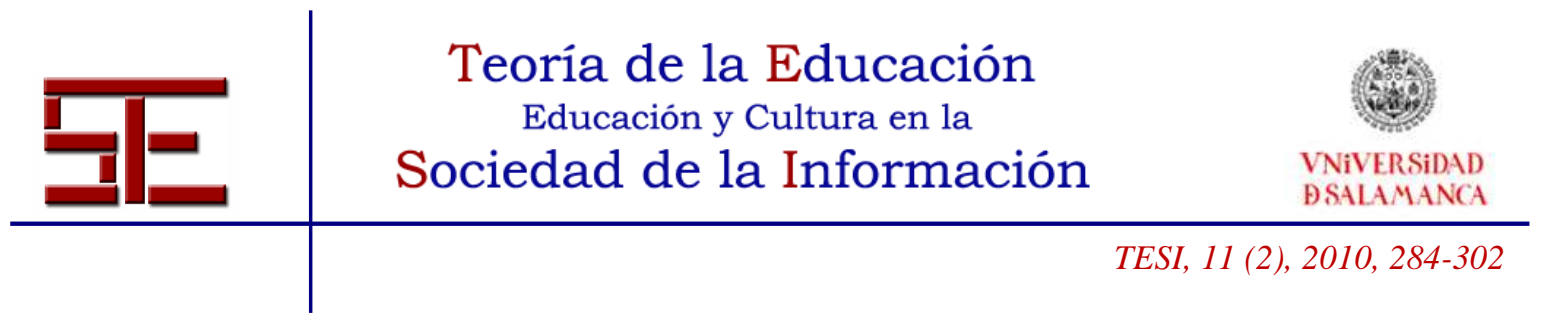

podría actuar como agente que ayude a los estudiantes a realizar un recorrido efectivo sobre el contenido de un curso en línea.

La incorporación de estos metadatos añade elementos semánticos que serán posteriormente interpretados por los ordenadores, en función de una gramática basada en una tabla de etiquetas que se encuentra almacenada en el ordenador y contra la cual se contrastan las búsquedas que se realizan. Aquí, la semántica a la que nos referimos es la que se maneja en el contexto informático, que verifica que las etiquetas de los objetos correspondan con las que se tienen almacenadas, determinando así si se corresponde con la semántica del sistema. Sin embargo, esto no indica el grado semántico que poseen los objetos y menos aún si éste se corresponde con el establecido en el entorno de aprendizaje. Esto podría dar lugar a un curso en línea que cuente con los metadatos y con un agente que realice búsquedas sobre ellos y que sea semánticamente inconsistente desde el punto de vista lingüístico, lo que dificultaría el trabajo del estudiante al enfrentarse a ese entorno, impidiéndole relacionar el contenido del curso con el patrón semántico que tiene formado, o crearse uno errado.

La semántica es un componente de gran importancia en un entorno de enseñanzaaprendizaje, ya que permite a los estudiantes situarse en un contexto y establecerse un modelo mental que guíe su proceso de aprendizaje y le permita crear las relaciones entre los objetos allí presentes, generando conocimiento en función de lo descrito por ellos.

\section{3.- Concepto de semanticidad}

Siguiendo la definición clásica de Charles Morris, mientras que la sintaxis se ocupa de las relaciones entre símbolos, la semántica trata con las relaciones entre símbolos y significados. Eugenio Coseriu (2001) establece que el lenguaje se caracteriza por cinco universales, tres primarios: creatividad, semanticidad y alteridad, donde la creatividad caracteriza las formas de la cultura, entre éstas el lenguaje, que es la actividad que crea significados, es decir, crea signos y significaciones, y en esto consiste su semanticidad. Estos signos son siempre creados para ser entendidos por otra persona, por lo que desde el inicio pertenecen no sólo a quien lo crea, sino también al otro y en eso radica su alteridad. En este sentido, afirma Coseriu que "el lenguaje es la manifestación principal de la alteridad, de estar con otros característico del hombre". Los dos universales secundarios son historicidad y materialidad. La historicidad resulta de la creatividad y la alteridad, al presentarse la técnica de la actividad lingüística siempre bajo la forma de sistemas propios de comunidades históricas tradicionales, llamados lenguas. La materialidad resulta de la semanticidad y de la alteridad, ya que la semanticidad es un hecho de la conciencia, pero que no sale de ella. Para que la conciencia sea perceptible

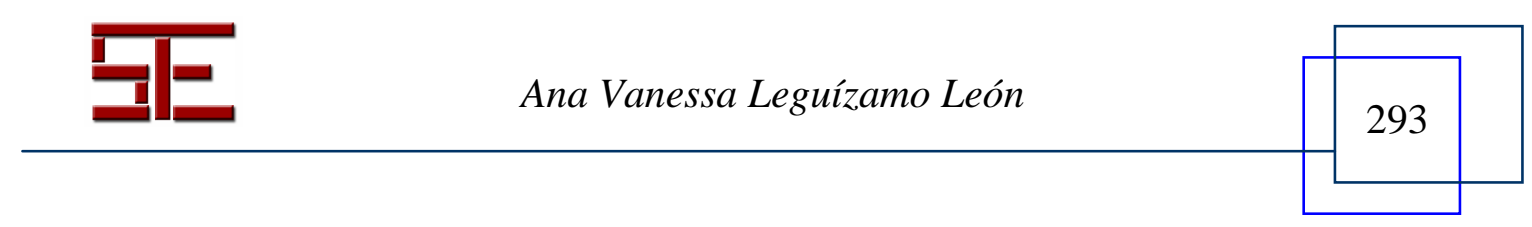




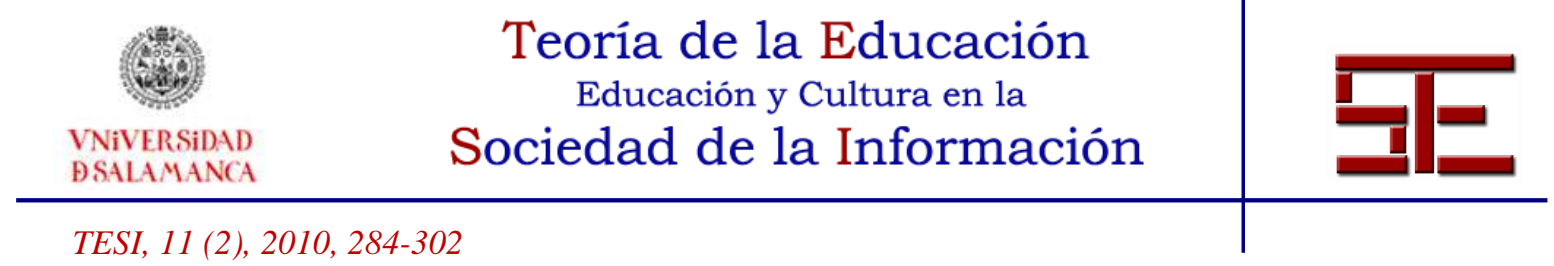

por otra persona debe estar representada en el mundo real por los significantes materiales.

Las dos funciones del lenguaje son nombrar y decir, lo que corresponde a la distinción entre léxico y gramática. Mientras que en el nombrar todo es lenguaje, como la organización del mundo en categorías y especies, en el decir se establecen las relaciones en este mundo y con este mundo, lo que constituye la modalidad semántica de estas relaciones, su "sustancia". En el contenido expresado y comunicado por las palabras, hay que distinguir entre designación, significado y sentido. La designación es la referencia a las "cosas" ajenas a los signos. El significado es la posibilidad objetiva de designación dada en los signos de una lengua a esa "cosa". El sentido es la finalidad de cada decir, el contenido propio de un discurso. Desde el punto de vista de Coseriu, el sentido es la finalidad del discurso, expresado por el significado y la designación, teniendo en cuenta que en ese proceso de construcción del sentido contribuyen también el conocimiento previo de las cosas y sus contextos. El contenido propio y exclusivamente lingüístico es, en consecuencia, el significado. Así, el lenguaje confiere el "ser" a las "cosas", no crea los entes sino su ser: los hace ser esto o aquello. El lenguaje no crea los árboles, sino su "ser árboles", y no plantas en general u otra especie. Al delimitar las características del ser, el lenguaje permite reconocer en el mundo los entes correspondientes a estas características y permite la posibilidad de realizar búsquedas en función de las "cosas" estableciendo nuevas delimitaciones, éstas ahora más objetivas, aplicadas en el mismo contexto de las cosas y para las cuales se pueden tener nuevos términos; por ejemplo, al hacer referencia a un árbol con manzanas, se añade una característica que delimita este tipo de árbol, un manzano, del resto de árboles posibles.

Para García Carrasco $(2005,8)$ "una situación cualquiera es para el sujeto (i) lo que a través de los pormenores, el fondo y el momento, la definen como objeto, elementos de los que los sentidos periféricos informan; (ii) a lo que se incorpora información acerca del estado interno del sujeto e (iii) información referente a experiencias anteriores con las que se asocia. Toda esta semanticidad podemos agruparla en dos grandes categorías: semanticidad informativa y semanticidad emotiva. Por una vía el sujeto elabora narración sobre los hechos, por la otra los hechos se presentan como una narración vivida por el sujeto. Por la primera vía transcurre la "noencia" (vía cognitiva) y por la otra la "vivencia" (vía emocional)".

Para Álvarez Rodríguez (2002), la semanticidad del pensamiento conlleva una dimensión de significación y de comprensión más allá del mero juego formal entre símbolos, una significación que siempre va mediada por la subjetividad y en ocasiones también por la intencionalidad del fenómeno mental.

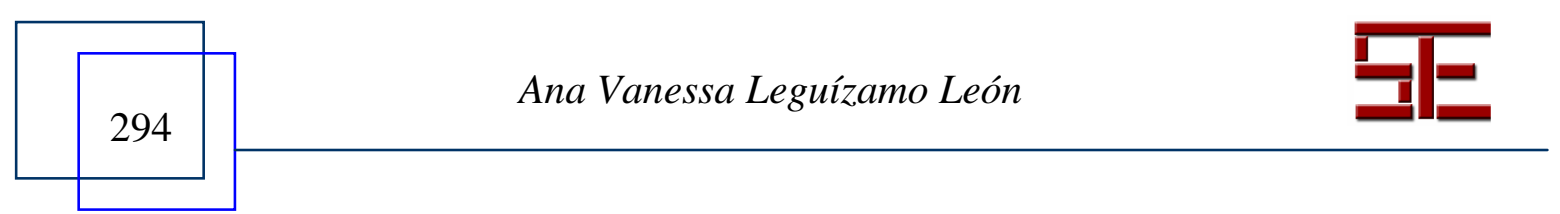




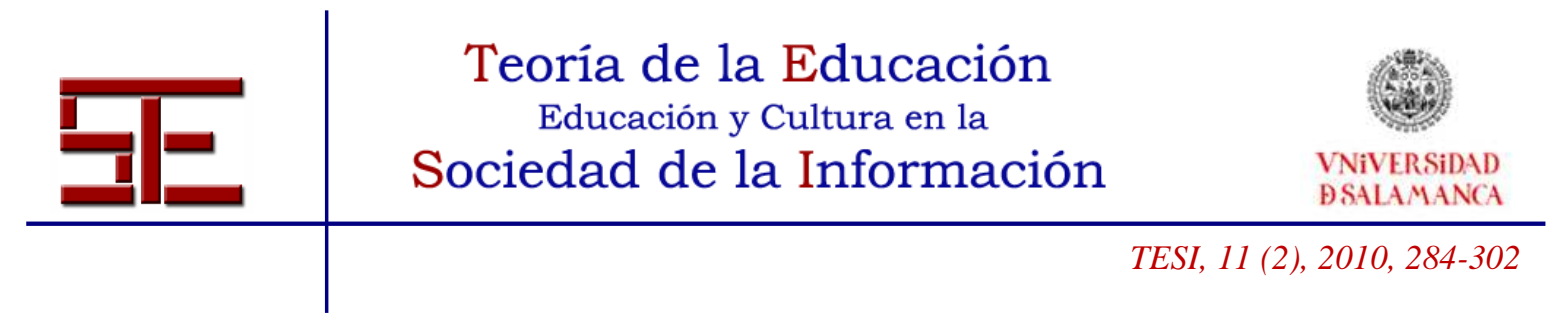

"La significación es el proceso que asocia un objeto, un ser, una noción, un acontecimiento, a un signo susceptible de evocarlos... Un signo es, por lo tanto un estímulo cuya acción provoca en el organismo la imagen recordativa de otro estímulo: la palabra evoca la imagen de la cosa" (Fernández et al., 1989, 25).

Este proceso de asociar significado a un signo tiene su base en la teoría de signos y en la psicología, que plantean que cualquier estímulo recibido deja una huella en el organismo que posteriormente puede volver a ser evocada al recibir nuevamente el mismo estímulo o alguno asociado a éste. Así, la mente humana relaciona la imagen de las cosas con la idea que de ella se ha formado. Todo signo se compone de un significado, que es su sentido o valor, y de un significante en virtud del cual se manifiesta el signo. El significado representa el contenido del signo y el significante la expresión utilizada para evocarla. Es posible tener distintos significantes para representar un mismo significado, por ejemplo, para hacer referencia al calor, es posible usar como significante la palabra calor como tal, o una imagen de un sol radiante, o un termómetro ambiental con una temperatura superior a los $30^{\circ}$ centígrados, y con cualquiera de estos tres significantes obtendríamos como significado la sensación térmica de calor. La significación viene a ser esa asociación que se da en la mente humana entre un significante y su significado. La dificultad comienza cuando el significante no se corresponde exactamente con algún esquema mental, por lo que es necesario recurrir a otros significantes que delimiten los rasgos distintivos del significante original para hacer efectiva la asociación con el significado que se referencia.

La significación de un concepto es descrita por la definición de dicho concepto, es decir, es el objeto mental ligado a un significante. La significación es por consiguiente, la relación entre un concepto y una forma o significante.

Según Fernández et al. (1989), la definición constituye la única forma completa de análisis semántico y es el puente entre la semántica y la lógica. Sin embargo, considera también que el análisis completo de los campos semánticos puede ser poco viable para determinar los rasgos distintivos de los significados.

La significación no se refiere a las cosas en cuanto existen, sino a lo que representan las cosas. La palabra ordenador significa lo que es un ordenador, la infinita cantidad de ordenadores que existen, de tipos de ordenadores e incluso los que aún no existen. Por eso la designación mediante el lenguaje es también importante en el proceso de definición, ya que se manifiesta y está condicionado a través de la significación. La significación y la designación hacen referencia a la semasiología y a la onomasiología respectivamente. Los campos semasiológicos acotan todas las significaciones que puede

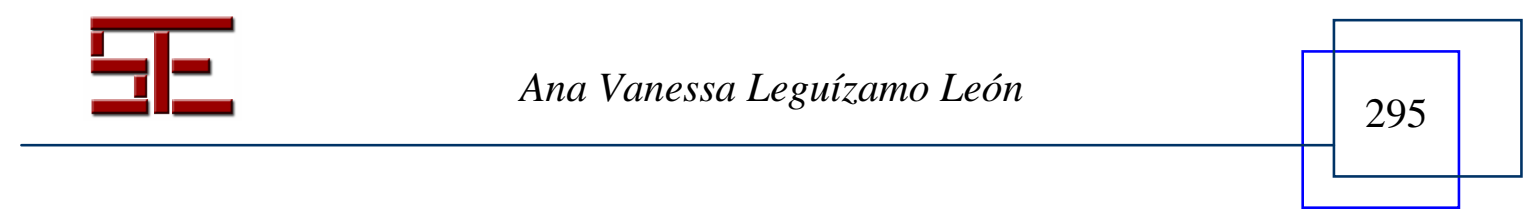




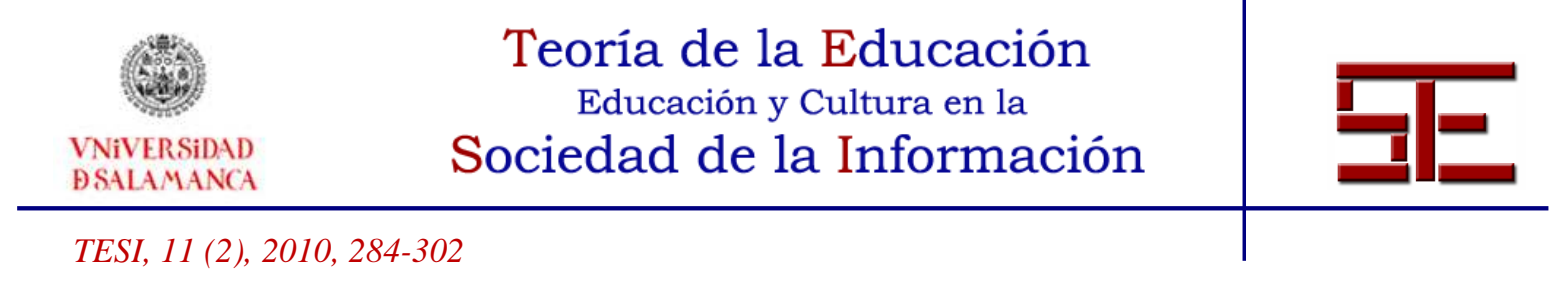

tener un significante, conduciendo a través de esas acepciones a un conjunto de representaciones mentales que coadyuven a la significación. Los campos onomasiológicos constituyen un campo de designaciones, es decir, a partir de un concepto expresa todos los posibles significantes asociados a él.

En este mismo orden de ideas, otra concepción del significado es la que entiende a la significación o concepto como una serie de operaciones y que se resume en que el significado de una palabra es relativo a su uso. Esta definición hace suponer que el verdadero significado de una palabra es aquel que se consigue observando lo que una persona hace con ella en un contexto determinado, no lo que dice de ella. Esta concepción es llamada tendencia operacional o contextual y establece que la significación de una palabra no puede captarse exactamente, ya que sus funciones significativas son sólo perceptibles con sus diversos enlaces significativos $o$ contextuales. En función de esto, concepto y significación no son equivalentes, la significación es más extensa al involucrar además de significado, relaciones contextuales entre lo dicho y lo hecho, mientras que el concepto es sustentado sólo por la palabra. Esta teoría tiene el mérito de definir el significado en términos empíricos o puramente contextuales. Ejemplificando esto se puede ver el significado de la palabra blanco en diversos contextos. De por sí, la palabra blanco representa un color, o más bien la falta de él y evoca entre otras cosas, limpieza, pureza. Si la usamos como adjetivo, podríamos hacer referencia al pan blanco o al vino blanco, haciendo referencia a que ambos son de colores más claros que los demás, sin llegar a ser ciertamente blancos. Si la utilizamos como sustantivo, podríamos remitirla al objetivo hacia el que se dirige algo, por ejemplo, a una diana en caso de estar practicando tiro, pero diferente significado tendría en el caso de decir soy el blanco de la ira de mi jefe, ya que en este caso el objetivo es metafórico, es una persona hacia la que se dirige un ensañamiento en una relación jerárquica de poder. Otra metáfora donde se utiliza esta palabra es al decir que nos quedamos en blanco, al querer expresar que no sabemos qué hacer en un momento o ante una situación determinada.

Por otra parte, el significado semántico de una palabra u objeto es relativo al contexto en el cual se encuentre, así se puede tener palabras sintácticamente idénticas, pero que, dependiendo del contexto en el que se utilicen, tengan significados diferentes. Tal es el caso de la palabra matriz, que si se encuentra en un contexto médico hace referencia a la parte del órgano reproductor femenino donde se desarrolla el feto hasta el momento del parto. Pero si la ubicamos en un contexto matemático hace referencia a un conjunto de números o símbolos ubicados en filas y columnas.

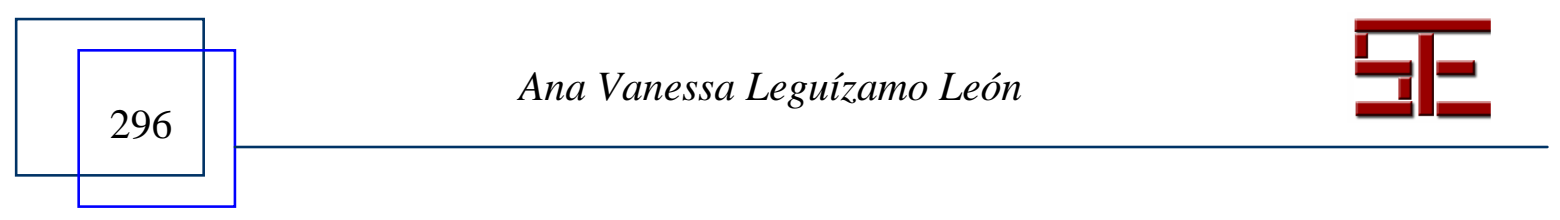




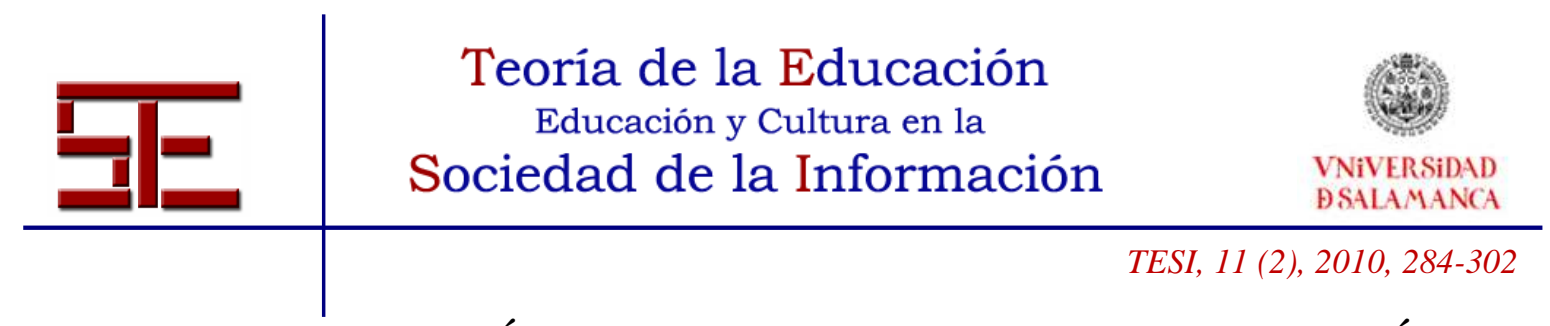

\section{4.- EL ENFOQUE SEMÁNTICO COMO ELEMENTO DE NEGOCIACIÓN DE SIGNIFICADOS}

En educación es común hablar en términos de conceptos y sistemas conceptuales. Un sistema conceptual es un patrón temático de relaciones semánticas en un tema, un patrón que se reconstruye una y otra vez casi de la misma forma por los miembros de una comunidad, que puede ser una pequeña élite científica o un espacio educativo donde se pretenda aprender el sistema en cuestión. Sabemos que los conceptos están interconectados en sus significados y que el uso de los sistemas de conceptos conectados dan poder al razonamiento. No es inusual plantearse que la enseñanza se basa en buena medida en enseñar sus sistemas conceptuales. Ahora, si los conceptos no existen como ideas, entonces se debe recurrir a patrones de relaciones entre eventos y fenómenos conocidos que puedan ser percibidos y estudiados.

El lenguaje oral y escrito, aun con el orador más explícito o en el libro más cuidadosamente escrito, únicamente proporciona pistas para determinar el significado total de un discurso o texto. Las palabras que escuchamos o leemos representan sólo la punta del iceberg del significado. Lo que escuchamos debe ajustarse a algún patrón temático familiar para nosotros, científico o cotidiano, para tener sentido. Esto es porque tener sentido significa identificar las relaciones semánticas entre las palabras o frases utilizadas, es decir, escucharlas dentro de un patrón semántico. Dicho de otra manera, dar sentido a cualquier cosa que escuchamos o vemos significa vincularla con alguna otra cosa que nos es familiar, ya que la hemos escuchado o visto antes. Estas vinculaciones pueden darse una tras otra de manera indefinida, por lo que constantemente estamos añadiendo elementos a los patrones semánticos que ya conocemos. En este contexto, Lemke $(1997,112)$ introduce el concepto de patrón temático, que define como: "Un patrón temático es una forma de visualizar la red de relaciones entre los significados de los términos clave en el lenguaje de un tema particular. Esos términos o sinónimos equivalen a formas de expresar los ítems temáticos del patrón. La gramática y el discurso al hablar y escribir proporcionan los medios de expresar las relaciones semánticas entre estos ítems".

Un patrón temático muestra lo que tienen en común las diversas formas de decir la misma cosa. Describe un patrón compartido de relaciones semánticas. Este patrón se repite en diferentes momentos durante una clase y de una clase a la siguiente. Es el mismo patrón que aparece en los libros de texto y en los exámenes. Es el patrón que los alumnos deben dominar para lograr el aprendizaje de un tema en cuestión. Estos patrones están formados por conceptos o ítems temáticos y relaciones semánticas entre ellos, que a su vez pueden ser patrones temáticos más pequeños, por lo que son útiles al vincularlos unos con otros. Los patrones semánticos son necesarios para dar sentido a lo

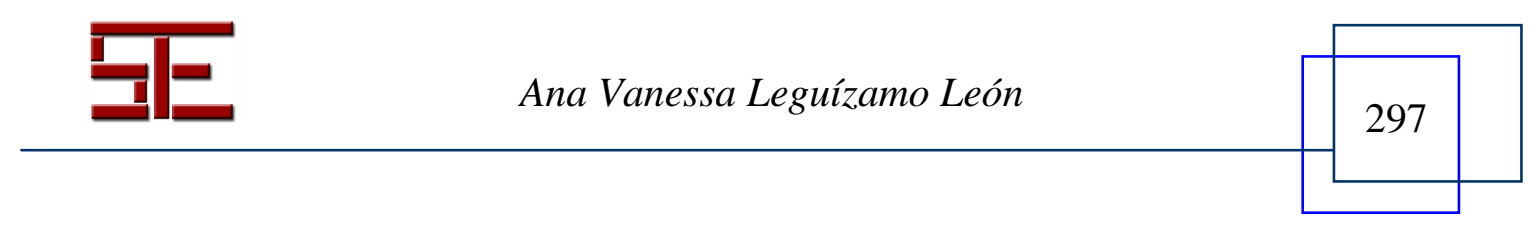




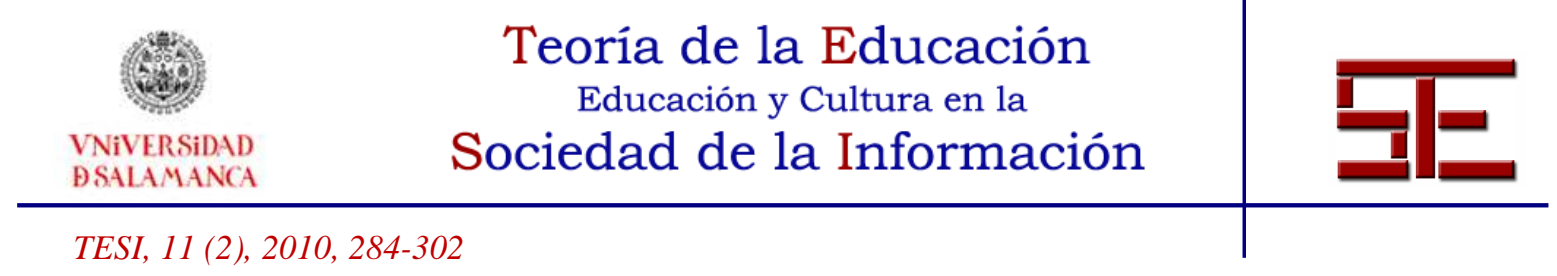

que se dice o lee. Cuando construimos un significado o una relación de significados entre ítems temáticos, probablemente lo estamos reconstruyendo en función de un modelo que alguien previamente construyó, aun si no utilizamos las mismas palabras pero reproducimos el mismo patrón de significado.

En muchos casos lo que se dice pareciera carecer de patrón ya que se supone que los que escuchan pueden llenar los espacios faltantes, al dar por sentado que ellos conocen el patrón al que se hace referencia y que lograrán determinar con mucha precisión lo que se quiso decir. Sin embargo, el lenguaje por naturaleza tiende a ser ambiguo, por lo que es imposible definir exactamente cada palabra en cada oración, en cada contexto y lograr además que cada relación semántica, cada sinónimo o cada palabra alternativa sea explicita y no ambigua, por lo que los alumnos de una clase frecuentemente pueden hacer vinculaciones muy diferentes de los ítems temáticos expuestos, lo que lleva a que se formen interpretaciones diferentes e infieran patrones temáticos diferentes para un tema concreto. Con base en esto, es importante que en la actividad docente se aprenda a aprovechar las flexibilidades del lenguaje para evocar en los alumnos los patrones temáticos adecuados para un tema en cuestión. Para ello es necesario aprender a dar el mayor significado posible a los patrones temáticos que se deben usar, utilizando para ello las ventajas del diálogo, el doble sentido y la oportunidad para construir patrones temáticos compartidos que faciliten una mejor comunicación y posterior construcción de significados.

\section{1.- Factores de la semanticidad que influyen en los proyectos pedagógicos mediados por tecnología}

Una experiencia educativa de calidad consiste en la integración dinámica de contexto y contenidos creada y promovida por un profesor competente tanto en el ámbito educativo como en el organizativo. El enfoque tradicional, que consiste en dar clases y que promueve poco el pensamiento crítico o la formación de ideas, va en contra de los esquemas educativos actuales que demandan habilidades cognitivas, afectivas y psicomotoras no sólo para la adquisición de conocimiento sino para la aplicación de ellos en contextos reales, necesarias para una educación continuada a lo largo de la vida. Los entornos virtuales de formación pueden ser utilizados como medio para apoyar y promover la práctica de dar clases, sin embargo, su impacto consiste en aplicar nuevos enfoques que se beneficien de las posibilidades interactivas que ofrece. El valor de estos entornos está en su capacidad para promover la comunicación y el desarrollo del pensamiento y construir así significado y conocimiento. Así, el aporte esencial no sólo es el facilitar el acceso a la información, sino el potencial comunicativo e interactivo que aporta a la experiencia educativa. Esta interacción trasciende a la transmisión unilateral de contenidos y extiende la comunicación interpersonal dentro del proceso

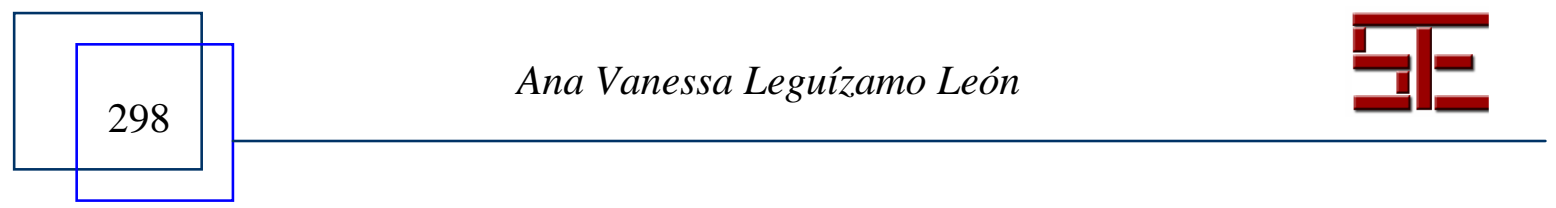




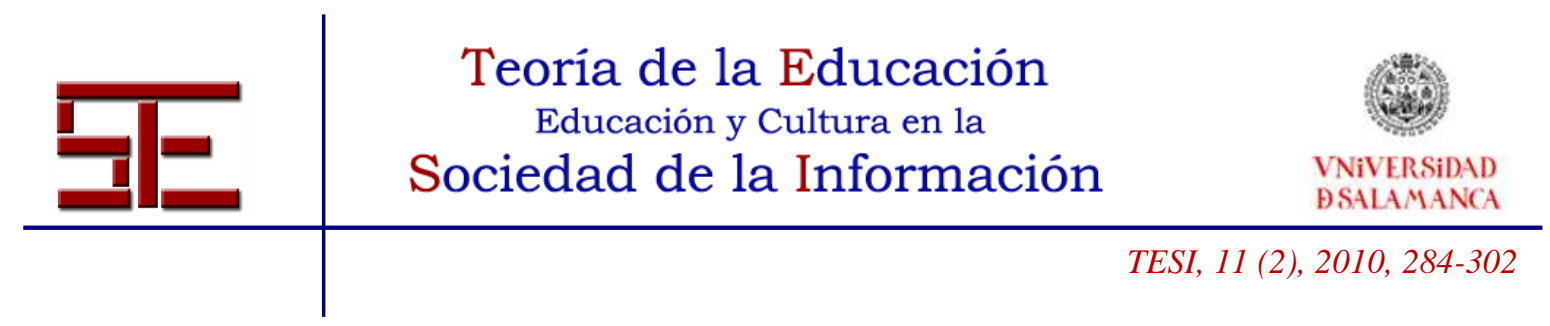

educativo. El potencial transformador de los entornos virtuales de formación se encuentra en proveer mejores medios para procesar, dar sentido y recrear toda la información disponible (Garrison \& Anderson, 2005).

Cada uno de los elementos que se incluye en un entorno de formación virtual debe tener un grado de semanticidad asociado al contexto en el cual se esté desarrollando el aprendizaje, contribuyendo a incrementar el grado semántico del entorno en sí. Así, cada objeto debe tener una intencionalidad pedagógica que aporte significado para el estudiante, evocando el patrón temático que se está trabajando en el entorno. La semanticidad de cada objeto tiene que estar bien definida, promoviendo la negociación de significados por parte del estudiante, generándole inquietudes que pueda ir resolviendo al establecer relaciones semánticas entre los objetos presentes en el entorno y sus conocimientos previos, y a medida que se desarrolla este proceso, ir construyendo su conocimiento.

El aprendizaje con entornos virtuales de formación requiere orientación en el espacio de información complejo y no lineal que representan los entornos virtuales de formación, una tarea no trivial que en ocasiones puede dar como resultado que los estudiantes se encuentren "perdidos en el hiperespacio". Para facilitar la orientación, los estudiantes deben construir una representación mental del espacio de información además de su representación mental de los contenidos de aprendizaje. En consecuencia, varios estudios (Edwards \& Hardman, 1999; Scheiter \& Gerjets, 2007) se han enfocado en los efectos de las ayudas de navegación diseñadas para ofrecer orientación hiperespacial y facilitar el desplazamiento en el espacio virtual. Sin embargo, Schnotz \& Heiß (2009) consideran que además de la orientación hiperespacial se debe proveer también orientación semántica, ya que los estudiantes pueden tener dificultades en la construcción de una representación mental coherente del contenido de aprendizaje. La falta de elementos de orientación semántica en los entornos virtuales de aprendizaje puede generar una sobrecarga en la memoria de trabajo de los estudiantes y en consecuencia llevar a que los alumnos pierdan el objetivo de aprendizaje, se enfrenten a dificultades en la identificación del tema principal y les sea complicado reconocer macroestructuras semánticas en el material didáctico. Es por esto que el aprendizaje utilizando entornos virtuales de formación debe apoyarse no sólo en ayudas para la orientación espacial, sino también en "andamios" semánticos que soporten la comprensión y construcción del conocimiento por parte de los estudiantes. En los materiales didácticos tradicionales, el andamiaje ${ }^{1}$ semántico se provee a través de organizadores o epítomes, objetivos de aprendizaje, preguntas orientadas a problemas y resúmenes. Hardy et al. (2006) afirman que el andamiaje semántico apoya dos elementos clave en los procesos instruccionales (1) la estructura de las tareas que permite a los estudiantes enfocarse en los aspectos importantes y (2) apoyar a los

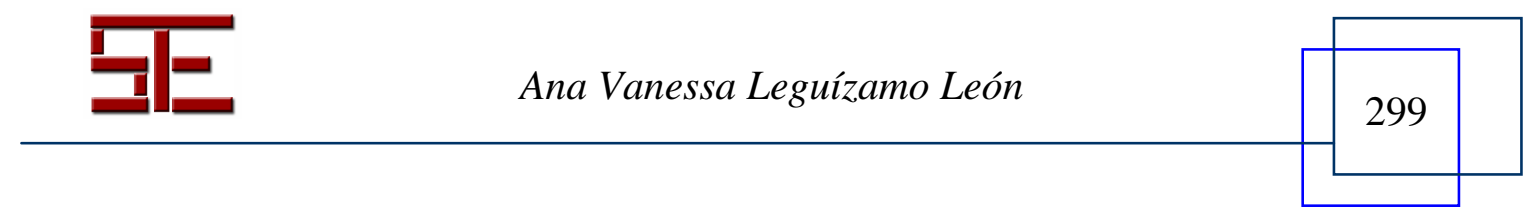




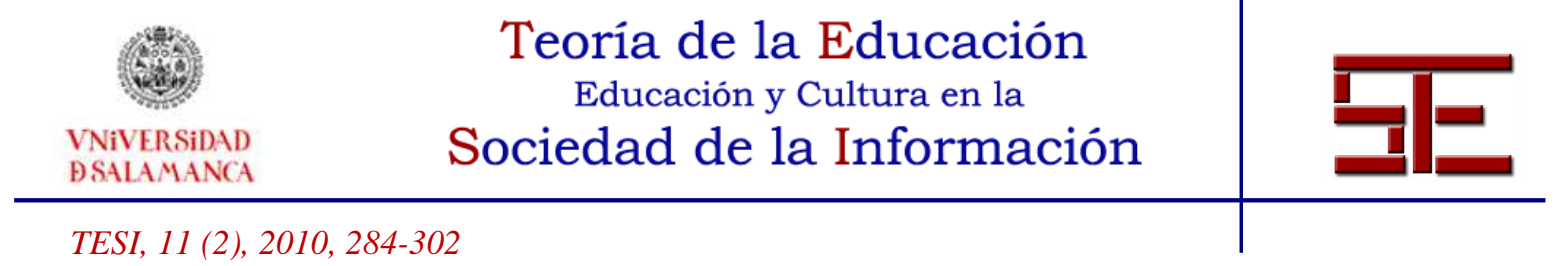

alumnos en la reflexión de sus ideas en un contexto más amplio. Asimismo, indican que el andamiaje apoya la coherencia de la formación mediante la activación de los conocimientos previos del estudiante, dirigiendo sus actividades cognitivas mediante la elaboración de contenidos que provean andamiaje semántico y facilitando la construcción de estructuras semánticas. Aprender en entornos virtuales sólo puede ser eficaz en la medida en que los alumnos hagan adecuado uso de ellos, igualmente aplica esto a la utilización de andamiaje semántico en el aprendizaje hipermedia.

\section{5.- CONCLUSIONES Y PERSPECTIVAS}

El estudio de la semántica en entornos virtuales es un área que ha sido poco estudiada, aun cuando se conoce su importancia como agente de negociación de los significados que obtendrán los estudiantes al trabajar con la plataforma que se haya seleccionado. El análisis del concepto de semanticidad aplicado a un entorno virtual de formación virtual permite obtener una visión clara de la importancia del componente semántico en ese contexto, que facilitará o entorpecerá el aprendizaje del estudiante en su tránsito por un entorno virtual de formación. En este sentido, el andamiaje semántico se constituye como un elemento a tener en cuenta en el diseño de estos entornos, con el fin de apoyar los procesos instruccionales en la estructura de las tareas y promover la reflexión de los estudiantes en su proceso de aprendizaje apoyado en la tecnología digital.

El contexto semántico en el que se involucre a los estudiantes en un entorno virtual de formación influirá en el proceso de apropiación del conocimiento que ellos lleven a cabo, por lo que se constituye en una línea en la cual se puedan realizar futuras investigaciones, en función de la inclusión de objetos digitales que incrementen la semanticidad de estos entornos.

\section{6.- AGRADECIMIENTOS}

La presente investigación ha sido financiada por el Consejo de Desarrollo Científico y Humanístico de la Universidad Central de Venezuela. Está siendo llevada a cabo en el "Laboratorio de diseños educativos multimedia y teleeducación" del Instituto Universitario de Ciencias de la Educación de la Universidad de Salamanca.

\section{7.- REFERENCIAS}

Aho, A., Sethi, R. \& Ullman, J. (1990). Compiladores: Principios, técnicas y herramientas. México: Addison Wesley Iberoamericana.

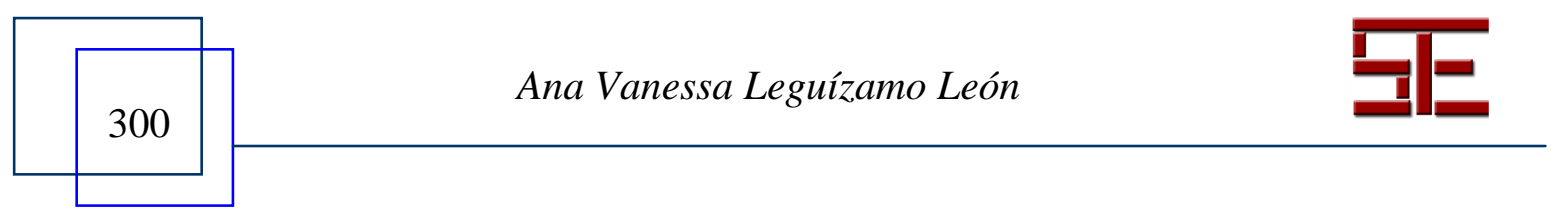




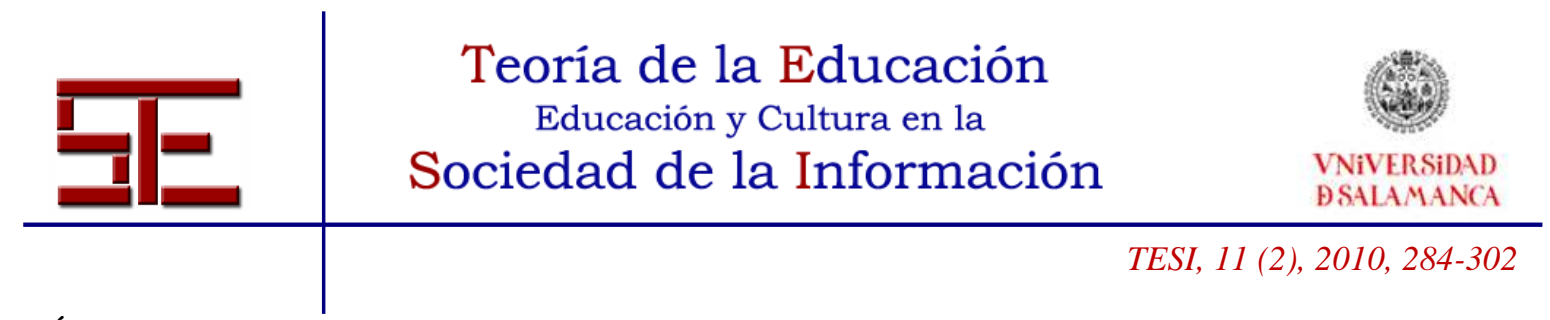

Álvarez Rodríguez, A. (2002). Propiedades nucleares de los fenómenos mentales según searle: Intencionalidad, subjetividad, semanticidad. Revista de Filosofía, 27 (2), $389-417$.

Bruner, J. (1984). Acción, pensamiento y lenguaje. Madrid: Alianza Editorial.

Cabero, J. (2006). Bases pedagógicas del e-learning. Revista de Universidad y Sociedad del Conocimiento, 3 (1).

Coseriu, E. (2001). Dix thèses à propos de l'essence: Du langage et du signifié. Revista Texto! vol. VI, N². Consultado en abril 2009. http://www.revuetexto.net/Inedits/Coseriu_Theses.html

Edwards, D. M. \& Hardman, L. (Eds.). (1999). Lost in hyperspace: Cognitive mapping and navigation in hypertext environment. Norwood, New Jersey: Ablex.

Fernández, A., Hervás, S. \& Báez, V. (1989). Introducción a la semántica. Madrid: Editorial Cátedra.

García Carrasco, J. (2005). Las formas de la alfabetización cultural: Comprensión, iniciación y creación en las comunidades de información. Consultado en abril, 2009,

http://iuce.usal.es/doctorado/documentos/joaquin/LasFormasDeLaAlfabetizacionCu ltural.pdf

Garrison, D. R. \& Anderson, T. (2005). El e-learning en el siglo XXI. España: Ediciones Octaedro.

Gros, B. (2000). El ordenador invisible. Barcelona: Gedisa.

Hardy, I., Jonen, A., Möller, K. \& Stern, E. (2006). Effects of instructional support within constructivist learning environments for elementary school students' understanding of "floating and sinking". Journal of Educational Psychology, 98, 307-326.

Hauriou, M. (1925). La théorie de l'institution et de la fondation. Essai de vitalisme social. En aux sources du droit: Le pouvoir, l'ordre et la liberté. Cahiers de la Nouvelle Journée, 23.

Lemke, J. (1997). Aprender a hablar ciencia. Lenguaje, aprendizaje y valores. España: Editorial Paidós.

Martín Barbero, J. (2003). La educación desde la comunicación. Colombia: Editorial Norma.

Morales, E. (2007). Gestión del conocimiento en sistemas e-learning, basado en objetos de aprendizaje, cualitativa y pedagógicamente definidos. Salamanca: Universidad de Salamanca.

Ortín, F., Cueva, J., Luengo, M., Juan, A., Labra, J. \& Izquierdo, R. (2004). Análisis semántico en procesadores de lenguaje (Vol. Cuaderno $\mathrm{N}^{\circ} 38$ ): Universidad de Oviedo, Departamento de Informática.

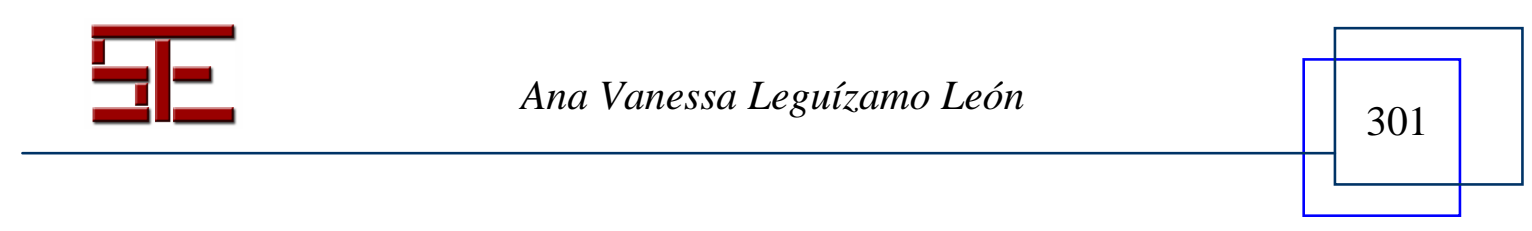




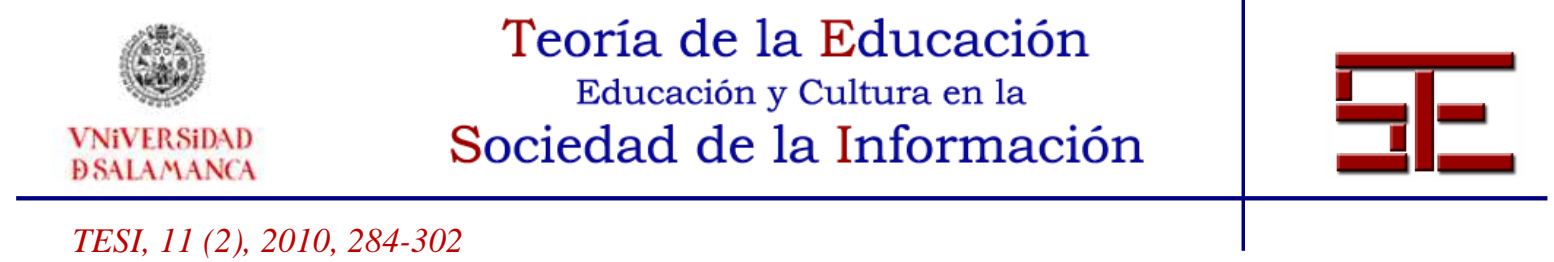

Ozollo, F. \& Osimani, J. (2007). Las significaciones del aprendizaje en los entornos virtuales en la educación superior. I Jornadas Nacionales de Investigación Educativa. En Universidad Nacional de Cuyo. Argentina: Mendoza.

Scheiter, K. \& Gerjets, P. (2007). Learner control in hypermedia environments. Educational Psychology, 19, 285-307.

Schnotz, W. \& Heiß, A. (2009). Semantic scaffolds in hypermedia learning environments. Computers in Human Behavior, 25, 371-380.

\section{NOTAS}

${ }^{1}$ Andamiaje es un concepto introducido por Jerome Bruner a raíz de las investigaciones de la Zona de Desarrollo Próximo desarrolladas por Vygostky. Bruner refiere que el andamiaje es un tipo de apoyo dirigido que familiares, maestros o expertos ofrecen con el fin de encauzar el comportamiento de un aprendiz en la realización de una tarea (Bruner, 1984).

Para citar el presente artículo puede utilizar la siguiente referencia:

Leguízamo León, A.V. (2010): Aspectos semánticos en los entornos virtuales de formación, en Juanes Méndez, J. A. (Coord.) Avances tecnológicos digitales en metodologías de innovación docente en el campo de las Ciencias de la Salud en España. Revista Teoría de la Educación: Educación y Cultura en la Sociedad de la Información. Vol. 11, n ${ }^{\circ}$ 2. Universidad de Salamanca, pp. 284-302 [Fecha de consulta: dd/mm/aaaa].

http://campus.usal.es/ revistas_trabajo/index.php/revistatesi/article/view/7082/7115 